\title{
Investigator by Role in Study
}

National Cancer Institute

\section{Source}

National Cancer Institute. Investigator by Role in Study. NCI Thesaurus. Code C70722.

The characteristic that defines the responsibility of the investig ator on a particular study. 